\title{
Analysis of the (Im)Possibility of Social Retrogression in the Brazilian Constitutional Order
}

\author{
Matheus Medeiros Maiaa, Rafael Soares Duarte Moura ${ }^{a}$
}

\begin{abstract}
The subject of this research is the study of the principle of non-retrogression, implicitly confirmed in the Constitution of the Federative Republic of Brazil in 1988. Because of the economic and financial crisis context Brazil is going through, the public resources directed to the materialization of constitutionally assured social rights started to be rationalized, with reflections at the legislative level with the amendment of laws that receded in terms of social order. In this scenario, the principle of non-retrogression is put under analysis as constitutional norm it is, with its absolute or relative nature. By employing a scientific-deductive method and a bibliographic procedure, it is concluded that the non-retrogression principle must not have an absolute nature, but rather a relative one. Therefore, in order for a norm to result in a legitimate social retrogression, it has to be bound to the sieves of reasonability and proportionality, due legislative process and to the protective sphere of the existential minimum for citizens.
\end{abstract}

\section{Keywords}

Non-retrogression principle, Constitution of the Federative Republic of Brazil 1988 (CFRB/88), proportionality and reasonability

The promulgation of the Constitution of the Federative Republic of Brazil 1988 (CFRB/88) was the most important political and legal milestone concerning the recognition and consolidation of legislative effectiveness of fundamental rights for Brazilian citizens, especially for having been the constitutional diploma that broke with the historic period of the military dictatorship that had been established between the years 1964 and 1985, a time marked by authoritarianism and violation of fundamental rights.

Despite the extensive Brazilian constitutional history that since the proclamation of independence from the Kingdom of Portugal in 1822 counts eight constitutions, is a fact that constitutional diplomas previous to the CFRB/88 had weak legal certainty and many of their legal devices, including the clauses of protection of fundamental rights, were only regarded as political recommendations that lacked binding legal force.

The CFRB/88 elevated the Federative Republic of Brazil to a Democratic and Social State of Law which, in its extensive list of fundamental devices fostered, in addition to individual rights and guarantees, rights that

\footnotetext{
aFaculdade de Direito Santo Agostinho (FADISA), Brazil

\section{Correspondent Author:}

Matheus Medeiros Maia, Rua Professor Monteiro Fonseca, $n$. 1347-A, Vila Antônio Narciso, Montes Claros, MG, Brazil, Code Number 39400-804

E-mail: mmedeirosmaia@hotmail.com
} 
safeguard the social well-being of citizens.

In this scenario, considering that the fundamental rights of individual nature and immediate effectiveness faced obstacles to attain materialization, the social rights of programmatic nature found barriers even more difficult to be transposed, as those require positive state provider rights that directly involve the spending of public resources which, in turn, are always scarce. That means that the effectiveness of social rights, in addition to facing obstacles relating to programmatic nature and, therefore, weak legal certainty in many of its rules, was also subject to the conditions of public treasure reserves.

With the promulgation of the $\mathrm{CFRB} / 88$, which content was inspired by the theoretical lines of neoconstitutionalism, constitutional rules started be seen as protagonists in the Brazilian legal system, and the fundamental rights have assumed unprecedented relevance in our constitutional history with their enforceability, in addition to extensive list of fundamental rights and individual guarantees, an item devoted to social order and one chapter, under the title "Fundamental Rights and Guarantees", directed to social rights which, from that moment, acquired a positive fundamental nature.

For example, the analytical CFRB/88 has honored social rights as it provides a series of labor rights in its Article 7, such as, the irreducibility of wages, the right to a minimum wage in an amount that meets the basic needs of workers, definition of a work journey not superior to eight hours daily and 44 hours weekly, in addition to bind the state to providing social and health assistance free of cost to citizens who cannot afford such services, among several other social prerogatives that now hold fundamental status.

In spite of many of the fundamental rules of social rights having a programmatic nature, i.e., establishing social goals or normative programs to be attained by the state through the actions of an infraconstitutional legislator, said regulations have been glimpsed by the constitutional doctrine and by Brazilian courts from new perspectives, reason by which they started to be seen as rules which effectiveness may be judicially demanded.

As a consequence to this trend, the Brazilian Judiciary Power had to start treating a number of demands of parties that justify the subjective right to judicial relief from state in the fundamental social rights regulations provided for in the CFRB/88. For example, many are the legal demands before the state that seek subsidizing medical treatments through public resources, based on the constitutional assumption that health is a right of all and a responsibility of the state. For the purpose of a better glimpse, see the content of Article 196 of the CFRB/88: "Health is a right of all and a responsibility of the State, ensured by means of social and economic policies aimed at reducing the risk of disease and other ailments, and to the universal and equal access to actions and services for its promotion, protection and recovery”" .

In short, after the promulgation of the CFRB/88, the regulations of social rights started to have undeniable fundamental nature, and despite many commands are essentially programmatic, there are also rules that define rights, and, therefore, began to be judicially demanded, as is the case of the already mentioned phenomenon of judicialization of health, which has been growing dizzily in Brazil.

In this fashion, efficacy and juridicity started to be recognized in social rights regulations, including by the actions of Brazilian courts, which has established a dense atmosphere of constitutional protection of the social well-being of citizens.

\section{THE NON-RETROGRESSION PRINCIPLE: CONSTITUTIONAL NATURE AND FOUNDATIONS}

With the consolidation of the atmosphere of protection of fundamental social rights, the principle of non-retrogression was developed, based on the 
CFRB/88. This is not a constitutional regulation explicitly enforced, but rather implicitly due to a systematic interpretation of the regulating laws of fundamental rights.

The fact social rights were elevated to a fundamental level by the CFRB/88 caused the elementary assumptions of regulations of such nature to be also applicable to rules that regulate social well-being.

Thus, as the system of constitutional protection of rights related to the civil freedom of individuals precludes the possibility of the state to act normatively as to retrogress to a stage of a more limited legal protection of fundamental rights and individual guarantees, on the basis of this same reasoning, the state might not act normatively when the consequence glimpsed is an order of legal protection of social rights less beneficial to citizens than the one preceding the regulatory action. That is due to the fact the regulation of social rights, notwithstanding the programmatic nature of many of them, has a fundamental defining characteristics of rights, to some extent.

In addition, citizens are also guarded by the fundamental rule ensured by legal security, an intrinsic element of contemporary Democratic Constitutional States. In this sense, Sarlet (2008: 2) taught:

(...) It is true that the cry of the people for security (understood herein yet in a broad sense) and-as with the changes experienced by the legal phenomenon-due to a certain stability of legal relations, makes a fundamental value in all and any state that has the intention to deserve the title of Rule of Law.

In fact, the possibility of the infraconstitutional legislator to be entitled, in an unrestricted fashion, to amend rules that result in the mitigation of social benefits tardily earned by citizens, would configure a legally unstable state contrary to the very fundamental principles and purposes of the Brazilian Republic that sustain the figure of a democratic and social state that abides by law.

Moreover, one should not forget that the CFRB/88 established the imponderable dignity of the human person, which has in its core the definition of the existential minimum, as one of the foundations of the republic, understood as the minimum material conditions under which an individual is able to live with dignity and to fully exercise their freedom to pursuit what they want and value, as in the valuable lessons by Amartya Sen (2010).

Therefore, to this point, it is concluded that the principle of non-retrogression is a rule implicitly enforceable, as per the CFRB rule/88, and the result of a systematic interpretation of constitutional rules, to the extent its main grounds are on human dignity as the imponderable foundation of the republic, on legal security as a prerequisite of a Democratic and Social State of Law implanted in Brazil and on the fundamental nature of the constitutional rules that regulate social rights.

After providing grounds for the non-regression principle in the $\mathrm{CFRB} / 88$, the specific analysis of the principle of non-regression in the Brazilian constitutional order will be addressed next.

\section{RELATIVIZATION OF THE NON-RETROGRESSION PRINCIPLE AND THE NECESSARY CONSTRUCTION OF ITS CONDITIONS IN ANECONOMIC CRISIS SCENARIO}

After providing grounds for the non-regression principle, its applicability to the factual plan will be addressed next.

The applicability of the non-retrogression principle acquires other shapes when the state goes through crises in its economic-political system, as it occurring to Brazil. In such context of crisis, arises the analysis subject of this work, given the need of the public power to refrain from spending. This is because the rationalization of public spending always splashes on public policies and on social rights to provision that inevitably presuppose high financial costs. 
Two possibilities are glimpsed in this analysis, one of absolute nature and one of relative nature.

Under a rigid and absolute perspective, the constitutional principle of non-regression would be an insurmountable obstacle to any rule or construction of rule that would result in a less beneficial state of social protection to citizens. Thus, it would be legally impossible, for example, to amend laws that have retrogressive effects on social order through the legislative power, or judicial decisions through the judiciary power.

On the other hand, from the point of view that gives the principle of non-regression a relative nature, it could be submitted to the weighting technique through which, incidentally, the principle could be isolated to avoid social consequences of major consequences. In other words, normative measures or measures of public policies that would result in a minor setback would be exceptionally allowed, aimed at avoiding social damage that could cause major harm to collectivity.

This work embraces the already consolidated understanding that the fundamental principle of non-retrogression implicitly enforceable as per the CFRB/88 should be seen by the angle of relativity and not the absolute rigidity. This means that in spite of establishing a rule for a non-regression principle regarding social rights and guarantees, it makes room for weighting in the face of other principles, and that it may have its applicability suspended when its incidence is more detrimental to the social order. In this sense, Sarlet (2008: 25) taught:

(...) If it is correct to point out the existence of a high degree of consensus (at least in the national doctrine and case law and, generally, in European environments) regarding the existence of a protection against non-retrogression (...) the recognition of (...) such protection must not assume an absolute nature, notably concerning the achievement of social rights to be provided. In addition to this consensus (in the sense that there is a relative non-retrogression principle in terms of social rights), there is heated discussion about the extent of the protection against retrogression, being significant the differences in understanding recorded in the doctrinal and jurisprudential spheres, but also in the field of the solutions adopted by the positive law of each legal order individually considered.

Therefore, this work is in alignment with the understanding that in some cases, non-retrogression can be put aside, given its relative nature. This is because assigning an absolute nature to this principle could paralyze the socioeconomic organization of the state, which could have major impacts on public economy, given the high cost of providing social rights.

Assigning a relative nature to the principle of non-retrogression does not mean denying it of its legal certainty. In the opposite direction, the principle should only be suspended in major situations in which its suspensions proves more beneficial or less harmful to the social order that its application.

On the basis of this reasoning, certain requirements should be defined as to bind the legislator and the interpreters of law when their activities lead to retrogression. The importance of defining such conditions is to prevent the non-retrogression principle from having a merely discretionary content, at risk of losing its dense axiological content and becoming a piece of wording deprived of legal certainty, or a terrorist allegation that can be raised without technical criteria and substantiated by public administrators and legislators who usually also define the very limits of economic crises.

This work proposes the exceptional suspension of the non-retrogression principle, provided it meets some parameters that will be seen more thoroughly below.

\section{ON THE DIGNITY OF THE HUMAN PERSON AND THE CORE OF THE EXISTENTIAL MINIMUM IN THE CFRB/88}

The idea of dignity of the human person, before gaining normative power in the constitutions of Western States, was widespread in the plans of ethics and religion. The prevailing concept was that every 
human person has a dignity that is intrinsic and must be treated as an end in itself and not a means for achieving the goals that are alien to them, and yet, as we are all children of a same God, perfect and superior to mankind, we have the obligation of respecting others by treating all equally and with the same dignity (Barroso 2011: 272). There was not, therefore, a binding legal basis between people and sovereign states concerning the human person, who was seen as only from the ethical and religious value perspective.

However, after the barbarism committed by Nazi-fascist governments during World War II, such as the Jewish holocaust, the use of human persons in scientific experiments, the legal protection of human dignity became necessary beyond the religious and ethical/philosophical plans, and started to be safeguarded by law. In fact, Western countries started to have the principle of the dignity of the human person enforceable in their constitutions and it assumed, in the case of Brazil, the status of foundation of the Republic.

In the accurate lessons of Barroso (2011: 274):

The principle of dignity of the human person identifies a space of integrity to be guaranteed to all people for their existence only, in the world. It is the respect for creation, regardless of the belief behind its origin. Dignity is related both to freedom and to the values of the spirit under the material conditions of subsistence.

From this concept, it is obtained that all human persons hold dignity, whatever their origin, religion, political opinion, socioeconomic condition, thoughts, etc. All individuals should have respected, including by sovereign states, the physical and moral integrity for the human condition that we have. In addition, the notable professor relates the dignity of the human person to "the material conditions of subsistence", which concern the right to the existential minimum, inherently connected to the dignity of the human person.

Signaling this fine line between dignity and the existential minimum, Sarlet (2004: 59) defined dignity of the human person as a quality that is inherent to every human person, in the name of which everyone must be respected by society and by the state, involving a range of fundamental rights and duties that protect the person from inhuman or degrading treatment, as well as assure them the minimum vital conditions for a healthy life.

Thus, it is evident that human dignity is not a right. More than that, Novelino (2008: 207) taught that human dignity is an inherent attribute to any human person. In the line of this consolidated understanding, it is not for the legal system to recognize that people are or not worthy of dignity, as it is independent from normative declaration. The legal system must limit the means to make the respect, protection, and promotion of human dignity viable.

In this sense lies also the reasoning of Carvalho (2011: 585), by sustaining that:

(...) For the viability of the dignity of the human person, the state is responsible for the respect, protection, and promotion of fundamental rights. By virtue of the duty of respect, the state must not violate the rights; concerning the duty of protection, changes to the role of the state, of opponent to the rights for a role of custody and may not allow such rights to be violated; as regards the obligation of promotion, the state must provide the basic conditions (the minimum vital), either bynormative provisions or concrete benefits, for the full exercise of fundamental rights.

Therefore, from the moment the CFRB/88 elevated the dignity of the human person to foundation of the republic, it ensured to Brazilian citizens, especially to the victims of socioeconomic exclusion, the right to the minimum existential which, covered by the scope of said foundation, can be understood in a positive and in a negative dimension, as exposed by Sarmento (2008: 27):

The right to the minimum existential corresponds to the guarantee of basic material conditions for living. It has both a negative and a positive dimension. In its negative dimension, it operates as a limit, preventing the practice of 
acts by the state or by private individuals who deny the individual those material conditions essential for living with dignity. As for its positive dimension, it involves an essential group of rights to be provided.

The point reached conveys that, because the dignity of the human person is the foundation of the Federative Republic of Brazil and to guarantee the ones in need the right to material provisions for a minimum of dignity, when needed the state may use retrogression for the social order, but may not do so in a way that harms the sphere of the minimum social protection of individuals, once acting this way, the state would be contradicting one of its own foundations, which is the dignity of the human person.

To illustrate the situation, if the state grants a social benefit as an income complement directed to individuals who live in extreme poverty conditions and later due to an economic crisis and the consequent need to cut back public spending, it broadly revokes this same benefit, going against the negative dimension of the minimum existential, as it would be an act of state that would deprive the individual from a material condition the state itself provided at some previous moment, and which became indispensable to survive with dignity. This case would characterize an unconstitutional retrogression, since the effects would adversely affect the constitutional guarantee of the minimum existential to citizens, and the program beneficiaries would not cease to enjoy the minimum conditions for living with dignity.

Therefore, the guarantee of the minimum existential is also an important constitutional limiter to the possibility of the state to retrogress in terms of social order.

\section{REASONABILITY, PROPORTIONALITY AND CONSEQUENT OBSERVANCE TO A DUE LEGISLATIVE PROCESS}

In addition to the impossibility of resulting in privation for the spheres of protection of the minimum existential to citizens, social retrogressions must observe the parameters of proportionality and reasonability.

First, a distinction forgotten by many should be made between the concepts of proportionality and reasonability.

Although many treat the terms as synonyms, they differ as to the content of the values that compose their concepts. The lessons of Silva (2002: 31):

The rule of proportionality in the control of the restrictive laws of fundamental rights emerged by jurisprudential development of the German Constitutional Court and is not a simple agenda that vaguely suggests that the state acts must be reasonable, nor is it a simple analysis of the means-end relationship. In the form developed by the German Constitutional Court, it has a structure rationally defined, with sub-elements independent-analysis of adequacy, of necessity and proportionality in a strict sense-which are applied in a pre-defined order that give the rule of proportionality the individuality that clearly distinguishes it from a mere reasonability requirement.

It is understood that the idea of proportionality is more comprehensive than reasonability, as it involves three essential elements, to wit: adequacy, necessity, and proportionality in the strict sense.

On the other hand, Silva (2002: 32) considered that reasonability is but the adequacy of the means intended for the ends to which they are employed. In this line of reasoning, reasonability would merge with one of the elements of proportionality, which is adequacy.

Based on this understanding, in the Brazilian constitutional system, in order for a rule or interpretation to result in legitimate social retrogression, the result must be proportional and, consequently, reasonable.

Considering the idea of proportionality presented, the retrogression generated by the rule or interpretation must be adequate, necessary, and proportional in the strict sense.

For the retrogression to be adequate and reasonable, it must be preceded of dense technical and multidisciplinary studies proving that the normative 
action, despite the retrogression, is the most adequate to avoid citizens to bear major damage to the provision of social rights.

Likewise, the studies must evidence that the measure is actually necessary and that there are no other more efficient or more beneficial ways to avoid retrogression of major impacts on social order. The necessity requirement must be therefore fulfilled, as the retrogression rule must be in such situation for the lack of other equally effective means the state can use.

If the retrogression evidences adequacy and necessity, its proportionality must be analyzed in the strict sense, which "consists of weighing the intensity of the restriction to the fundamental right affected and the importance of the achievement of the fundamental right that collides with the retrogression and justifies the adoption of the restrictive measure” (Silva 2002: 40).

It is necessary to analyze if the restriction to fundamental rights arising from the rule in retrogression would not reach such a harmful level to individuals as to make it impossible. Considering what has already been treated in this work, proportionality in its strict sense should be on the focus of the sphere of protection of the minimum existential. In case of retrogression of a given social right so that results in violation to the minimum existential to a person, than such rule, despite reasonable and necessary, is disproportional, which has to be refused by the constitutional legislation.

Finally, there is reason to question how to ensure that a rule that is in retrogression can be reasonable and proportionate. The answer proposed by this work says that such verification should be made through a substantial and due legislative process.

During the process of elaboration of rules by the legislative power or even by the executive power by means of provisional measures, in addition to respect the formal requirements of validity of rules, justifications and motivations should be draw up with the degree of depth required by legislative materials.

The factual consequences of a rule in retrogression on social order can be extremely severe, and may cause deprivation of fundamental rights. Therefore, it is highly important that in the course of the drafting and approval of rules that lead to retrogression in the social order, the legislative bodies perform a prior and effective constitutionality control of the rules to be drafted. For that, it is necessary that the justifications for drafting the rules are seen not as mere formal requirements demanded for the respective valid approvals, but as an important instrument to evidence the reasonability, adequacy, necessity, and proportionality of the rule and, consequently, its compatibility with the network for constitutional protection of social order.

\section{CONCLUSIONS}

The legal rules in the abstract are not very effective when distant from the factual plan. In this fashion, having as background the situation of political and economic-financial crises Brazil is going through, with inflation indicators that have already exceeded $10 \%$ and the gradual devaluation of the Real (Brazilian official currency), it is suitable to analyze the necessity and the weighting parameters of fundamental social rules in the face of the implicit constitutional principle of non-retrogression. It was evidenced that, despite not expressed in the CFRB/88, the enforcement of said principle is implicit, based on the Social and Democratic State of Law and on the consequent core clause of legal certainty, and on republican basis of dignity of the human person.

Based on those constitutional foundations, the Brazilian Public Power observes the principle of non-retrogression as for the rights and guarantees earned by citizens, who after the CFRB/88 started to be protected by an extensive list of fundamental rights, among which are social and economic rights regarding a state of well-being.

Seeing that the Brazilian political-economic reality leads the state to adopt restrictive economic and social 
measures, the need for state actions that would lead to a retrogression in the social order became clear, and posed a central problem to labor, through which the parameters that legitimate this work of weighting were sought after.

It is concluded that, in view of the inseparable relationship between the constitutional rule and the actual factors inherent to the society, the content of principle on non-retrogression may not have an absolute nature to prevent any interpretation of retrogression in the fundamental social rules provided constitutionally.

However, in face of the need to establish some limits to the effectiveness of the rules or administrative acts that lead to retrogression in the social order, some conditions have been proposed as parameters to be observed when amending or interpreting rules that lead to retrogression.

First, retrogression must not be elevated to a rule; it is rather an exception applicable to certain cases of severe economic crisis, which must be specifically reasoned and evidenced in the course of the due legislative process through the action ofparliament members.

It must also be considered that retrogression will only be legitimate in so far as it is in accordance with the bordering principles of reasonability and proportionality, which shall be also evidenced through a due and substantial legislative process that demonstrates the technical reasons and motives of the adequacy and necessity of the rule. Finally, it was also evidenced that the legitimacy of the retrogression rules are, above all, restricted by the inviolable legally protected sphere of the minimum existential for citizens, from which an opposite understanding would be remove the imponderable foundation of human dignityfrom constitutional protection.

\section{Note}

1. Regulating the fundamental right to health, Law 8.080 as of
September 19, 1990 was amended in Brazil, implementing the Sistema Único de Saude in national scope, with provisions on the conditions for the promotion, protection and recovery of health, the organization and operation of relevant services.

\section{References}

Barroso, L. R. 2011. Contemporary Constitutional Law Course: The Fundamental Concepts and the Construction of the New Model. 3rd ed. São Paulo: Saraiva.

Brasil Constituição. 1988. Constitution of the Federative Republic of Brazil. Brasília, DF: Senado.

Brasil. 1990. Law 8.080 as of September 19, 1990. Brasília, DF: Senado.

Carvalho, K. G. 2011. Constitutional Law. 17th ed. Belo Horizonte: Del Rey.

Novelino, M. 2008. Constitutional Law. 2nd ed. São Paulo: Método.

Sarlet, I. W. 2004. Dignity of the Human Person and Fundamental Rights in Federal Constitution in 1988. Porto Alegre: Livraria do Advogado.

- 2008. Non-retrogression, Dignity of the Human Person and Social Rights: Expression of Possible Directive Constitutionalism. Retrieved December 23, 2015 (http://www.direitodoestado.com.br/rere.asp).

Sarmento, D. 2008. Legal Protection of Social Rights: Some Parameters Ethic-Legals. Retrieved December 23, 2015 (http://www.dsarmento.adv.br/content/3-publicacoes/16-a-p rotecao-judicial-dos-direitos-sociais-alguns-parametros-etic o-juridicos/a-protecao-judicial-dos-direitos-sociais.alguns-p arametros-etico-juridicos-daniel-sarmento.pdf).

Sen, A. 2010. Development as Freedom. São Paulo: Companhia das Letras.

Silva, V. A. da. 2002. "Proportionality and Reasonability." Revista dos Tribunais 798:23-50.

\section{Bios}

Matheus Medeiros Maia, undergraduate student in law, Faculdade de Direito de Santo Agostinho (FADISA), Brazil; research fields: constitutional law, fundamental rights, legal sociology, existential minimum and people in the streets.

Rafael Soares Duarte Moura, MA in law by Universidade Federal de Minas Gerais (UFMG), Ph.D. candidate at the Universidade de Brasília (UnB), Coordinator and Professor of Law, Faculdade de Direito Santo Agostinho (FADISA), Brazil; research fields: history of law, introduction and science of law, philosophy of law, legal sociology, legal hermeneutics, research methodology and theory of the constitution. 